\title{
Establishing Community Of Practice In The University College Hospital, Ibadan, Nigeria
}

\section{Lilian Onyedikachi Ikeazota}

University Library, Ekiti State University, Ado-Ekiti, Ekiti State, Nigeria

doi: 10.19044/esj.2016.v12n13p349 URL:http://dx.doi.org/10.19044/esj.2016.v12n13p349

\begin{abstract}
The aim of this paper is to discuss the need for a community of practice in the University College Hospital, Ibadan, Nigeria. The requirements for the community of practice involve the personnel, the facilities, and the process of establishing it in the institution. A well cultivated community of practice will exhibit the three elements of Wenger's model. Also, it would provide results as regards to problem solving, shared knowledge, and experience. In the era of recession and budget cuts, there is the need for library services to be maintained at its best. Effective and efficient innovative ways are applied in maintaining the library and the services it offers to its users. Sponsors should support the take-off. In addition, such goodwill will receive reward in terms of commendation once the group commences.
\end{abstract}

Keywords: library, Community of Practice, communication, domain

\section{Introduction}

The University College Hospital, Ibadan, Nigeria comprises of various departments including the School of Nursing. This department is tasked with the responsibility of producing trained medical personnel to improve the deteriorating health sector in Nigeria. Consequently, the University College Hospital Library has been designated as the National medical library in Nigeria. It provides resources for other libraries in the health industry. The library serves the information needs of staff and students of the College of Medicine. It is well-equipped with clinical journals and monographs.

Due to recent development, the use of information technology has penetrated all areas of human livelihood and the health sector. In addition, medical service delivery is not left out. It is necessary that the Medical School must also prepare the students not only on the medical practice, but 
also in understanding that information technology has stirred up some changes in medical service delivery.

The National Medical Library is faced with similar and several challenges as they produce Medical Doctors. Therefore, these doctors are required to overcome the challenges confronting the medical profession in the technology-driven and fast paced twenty-first century world. The central acquisition of electronic resources in recent years is commendable. Hence, feedback shows a poor usage spread and hitches ranging from slow internet connectivity to lack of service to non residential students and other less definitive challenges. Subsequently, there are very few librarians to give students support on electronic research. This is traceable to the fact that most librarians are not computer literates.

This report is to identify library personnel in the college to network. Also, it aims to learn and share experiences that will enable the medical library to work effectively and efficiently in the University College Hospital Library. It will also help lecturers and students to have a hitch-free experience when they come in contact with medical school library services.

Establishing a community of practice will help with the much needed transition from the tacit nature of skills, knowledge, and experiences to expressive learning organisation (Zappavigna, 2006). Stacey (2001) asserts that the knowledge localised in individual heads is largely tacit and expressed only in professional skills. He further stated that for knowledge to reach the organizational level, it should be shared or exchanged. It is normal for various individuals to be unwilling to share his or her knowledge with others, especially in the workplace where there is jostle for relevance and survival. Therefore, a properly constituted social learning environment will stimulate an organizational culture where the barriers to knowledge sharing can be defeated to create conducive learning platform at organizational level (Gheradi \& Nicolini, 2001).

\section{Community of Practice: Definition, Roles, and Structure}

The term "community of practice" was coined by Etienne Wenger (1998) who observed that the majority of accumulated knowledge is not received from those impositions of responsibility. On the other hand, it is shared amongst members of a team. He believes that learning is a social activity and that people learn best in groups.

A community of practice is a group of people who share a common concern on a set of problems, or interest in a topic and who come together to fulfil both individual and group goals (Wenger, McDermott \& Synder, 2002). Prior to the above, Wenger (2001) defined community of practice as a group of people who share a common concern on a set of problems or 
passion about a topic. Also, they increase or improve their knowledge by interacting with one another on an ongoing basis.

Communities of practice are formed by people of the same like-mind pursuing a goal and engaging in a process of collective learning in a shared domain of human endeavour. It is a group of individuals that helps each other to cope. Subsequently, it is not every locale that is a community of practice. Wenger (1998) went further to say that a neighbourhood, for instance, is often called a "community of practice".

A community of practice focuses on sharing best practices and creating new knowledge to advance a domain of professional practice. Interaction on an ongoing basis is an important part of this. A community's specific goals inform the appropriate activities and technologies that should support it. However, many virtual communities of practice rely on face to face meetings as well as web-based collaborative environments to communicate, connect, and conduct community activities.

A community of practice is a group of individuals which may be colocated or distributed, motivated by a common set of interests, and willing to develop and share tacit and explicit knowledge (Coakes \& Clarke 2004). One dominant factor of these definitions is the means by which communication is employed, which is mostly informal. Furthermore, personal contact empowers business relationships, builds trust, and resolves ambiguities especially in an establishment like the UCH Library.

\section{Characteristics of Community of Practice}

However, notable features of the community of practice are: mutual engagement, joint enterprise, and shared knowledge. This was clearly expressed in the three dimensions of Wenger's framework:

The Domain: This represents set issues which are considered to be important to the members. The main aim of their coming together is what they are passionate about. The interest in a medical library is scholarly researches and publications on Medicine and Nursing as a whole. It is an area of interest where membership identity is drawn from. Every member retains his/her membership on the basis of continuous commitment to the domain. Also, there should be a collective competence that distinguishes members from other people.

The Community: The community builds relationship amongst members that makes them learn from one another by involving in joint activities and discussions. It also helps one another to share information. This provides the basis for learning together. The community focuses on sharing, socialization, relations, discovery of research topics, and the critiquing of existing projects. 
The Practice: There must be a common professional practice connecting people before they can form their group and qualify as a community of practice. This involves the activities that the group develops in order to meet the goal of sharing and developing knowledge about their domain. They develop a shared repertoire of resources, experiences, stories, tools, ways of addressing recurring problems, and shared practices. Hence, such practices may include activities such as developing joint projects, attending meetings to learn from one another, and participating in conference.

\section{Roles of Community of Practice}

A community of practice plays an advanced role in an organization such as the library. The role includes but not limited to facilitating collaboration, identifying subject matters and developing them, filtering incorrect information and acting as rumour and destructive grapevine control mechanism, capturing intellectual capital, decreasing learning curves by preventing, re-inventing the wheels, sharing tested best practices, and increasing organizational learning (Wenger, 1998).

\section{Structure of a Community of Practice}

A community of practice is characterised by the following features:

Domain of Knowledge: This represents issues that are considered important to the members of the community. It focuses on the topic of the community and what brings them together. The purpose of their existence as members of the community is a common understanding of what matters to them.

A Community of People: The community represents the relationship among members who share a common vision, effective collaboration, and setup events binding them together. A sense of belonging and commitment is important. This makes them feel comfortable to seek advice, contribute, and discuss problems.

A shared Practice: This is what provides the communal language for communication. A shared practice could be specific guidelines, existing knowledge on the topic of interest, exploration of latest advances, and production of frameworks, ideas, tools, and documents on the basic needs. Also, the knowledge of a community is developed, maintained, and shared through a balance of joint activities.

\section{Benefits of Community of Practice}

With community of practice in place, knowledge management can be greatly advanced and improved in any organization. The goals and outcome of community of practice will deliver the following advantages among other 
far reaching organization wide improvement in value chain results. Some key benefits include:

- Improved problem solving capability and speed.

- It enhances professional competency and skills.

- It helps to retain talents.

- It promotes functional best practices.

- Builds up guiding strategies to employee's effectiveness.

- $\quad$ Free access to the hitherto tacit knowledge and experience of others.

- In house training- sharing and passing on knowledge and experience from senior to junior staff.

- Develop best practices through discussions and sharing of ideas.

- It uses the experiences of others instead of reinventing new ideas.

- Keep up-to-date at the time and pace of the individual member.

- Developing a spirit of oneness.

- Increased job satisfaction owing to the development of new problem solving abilities.

- Identification of and access to more knowledgeable colleagues.

- Trust between colleagues.

- Improved recognition and professional reputation among colleagues.

Furthermore, there is also a great increase in teamwork among members working in different units of the same section of an organisation. For example, the cataloguing, classification, circulation, readers, digital initiative, and other units in the library will interact and incubate better ways of serving the community of readers.

\section{What is expected of a Member of a Community of Practice?}

Every member in a functional community of practice is required to do the following:

- Show commitment by taking ownership of topic.

- Participate in meetings and forums.

- Share their knowledge and experience.

- Communicate freely with other members.

- Take advantage of computer mediated communication that will allow members to communicate through online chats.

- Identify areas that need improvement.

- Show enthusiasm.

Pemberton-Mavin \& Stalker (2007) have suggested that if functional community of practice should keep working, the following is expected. They include:

- $\quad$ There should be a coordinator to provide internal leadership and initiative to help the group sustain the drive.

- There should be a meeting facilitator and a secretary to ensure 
meetings hold regularly and that participants remember the ideas shared.

- $\quad$ Roles should be assigned to every member so that every member is involved (Stuckey \& Smith, 2004).

- Effective use of information and communication technologies. Digital discussion to connect outside of the regular sessions (Cordoba \& Robson, 2006).

- Effective use of tools such as social media, wikis, websites, or multiuser editing software like Google Documents.

- Face-to-face interaction is also used. A sense of belonging is created in the minds of the community members through a thoughtful face to face meeting (Stuckey \& Smith, 2007).

- Developing high level of trust.

- High degree of community bonding.

- Computer aided decision making resulting to better contributions arising from more ideas.

- Decisions are reflective of collaborative group intelligence.

\section{Challenges of Community of Practice}

- The possible challenge to the successful development of a community of practice is the balance of regulation and not enough structuring which will thereafter hinder performance (Coakes \& Clark, 2006).

- If the necessary tools that will assist in communication are not utilized, it can cause a crack in communication. These tools include listservs, wikis, websites, Google document, and others.

- The need of each member for validation and recognition can also be a minus if not properly harnessed.

- There can be a disrupted continuity if the leader is not focused and members are leaving suddenly as a result of lost interest (McDermott, 2004).

- $\quad$ Lack of concentration and attention from members due to competing obligations and tasks.

- Difficulty trying to sustain togetherness despite departmental, unit, section, and geographical spread.

- Changing values of the members can also be a hindrance to effectiveness and continuity of the group.

- Lack of trust between the foundation members and the peripheral or new members is a downfall (Pemberton, Mavin \& Stalker, 2007). 


\section{Disadvantages of Community of Practice}

- If the members have low IT skills, they would not contribute effectively.

- Smaller cliques can emerge within the community.

- It is costly to run and it consumes time if the infrastructure is poor.

- Larger community can defeat foundational objectives.

- Lack of trust among members can lead to poor output arising from poor contribution.

- Individual selfish interest. People may join to acquire some skills from other sections of the organisation and give it out to competitors.

\section{How to Cultivate Community of Practice in University College Hospital Library}

Cultivating a community of practice in an organizational context is an art. Community of practice is a social group that must emerge from the popular wishes and goodwill of the members. Therefore, it is necessary that the community is carefully cultivated and nurtured to grow. The invention of information technology in the medical library in the last few years has created a platform for effective and efficient take off.

\section{How does Communities of Practice Grow?}

The approach suggested here was adapted from McDermott (2004). It is a life cycle approach and has six basic elements.

Inquire: This is an exploratory phase. In exploring and making inquiries, note is taken concerning the audience's purpose, goals, and vision for the community or organisation. This will be done by conducting necessary assessment amongst the audience and stakeholders targeted to put forward the benefits accruable, identify areas of interest to the target groups, do cost analysis, and commence recruitment of core team.

Design: This is explaining the activities, technologies, group processes, and roles that will support or enhance the communities' goals. The ultimate goal of plan and design stage is to ensure that the community takes off with drive and energy. Overall, the design must enhance evolution, and ensure that excitement and familiarity are combined (Wenger, McDermott \& Snyder, 2002). Some principles identified as inclusive in the drive to achieve a balanced design are:

- Design for evolution.

- Enable dialogue.

- Welcome different levels of participation.

- Develop both public and private community spaces.

- Focus on value. 
- Combine familiarity and excitement.

Prototype: This is an act of leading the community or organization with a group of important stake holders to gain commitment, test assumptions, refine the strategy, and establish a success story.

The real evidence of a good design is known by subjecting it to practical test. Before the official launch, the design will be put to test by selecting a few appropriate community-oriented technology features to support the goals of the pilot, design the community environment and have a group test, decide on the community's organization and appearance, and implement the community's prototype. If the working is fine, the design is retained. However, if it fails, adjustment will be made.

Launch: Expose the community to a larger audience by welcoming new members and delivering immediate needs. At this point, the community is officially launched and the remaining people in the target audience who were not part of the design are invited. The audience is larger and is engaged in talks and actions to deliver some immediate needs.

Grow: This involves bringing everyone together in a forum that knowledge can be shared, embarking on group projects, and networking events that will meet the individual needs, group, and organizational goals. Thus, maximum participation is required in such forum.

Sustain: In some cases, the group has faint goals. Also, this can cause it to be closed or dissolved. In the academic library situation such as $\mathrm{UCH}$, continuity and sustenance is what is required. The knowledge created by the community will be cultivated, assessed, and preserved for the future.

\section{Conclusion}

The use of communities of practice is to facilitate quality improvements, provide some process support, coaching and logistic assistance, and generate high levels of satisfaction on the job and knowledge translation among participants. Communities of practice may take time to maintain, but the benefits of them far outweigh the challenges. In addition, the University College Hospital, Ibadan library, will be on the upward trend in delivering top rated Library services to her teaming patrons as well as boast of competent, efficient, and effective professional work force.

\section{References:}

Belzowski, Ladwig \& Miller (2013). Crafting identity, collaboration and relevance for academic librarians using communities of practices. Collaborative librarianship, vol5, no1.

Browyn Stuckey \& John (2004). Building sustainable Communities of Practice, in knowledge networks: innovation through communities of practice, ed. Paul M. Hildreth and Chris Kimble, pp.150-164 
Coakes \& Clark (2004). The concept of communities of practice, pp.93.available from: www.igi-global/chapter/concept-communitiespractice/10473 (accessed 11 Jan.2014)

Coakes \& Clark (2006). Encyclopedia of Communities of Practice in information and knowledge management. Hershey, PA: Idea Group Reference.

Cordoba \& Robson (2006). Understanding Communities of Practice to Support Collaborative Research, In Encyclopaedia of Communities of Practice in Information and Knowledge Management,eds. Elayne Coakes and Steve Clarke.Hershey, PA: $\quad$ Idea Group Reference, PP 558-564

Gheradi \& Nicolini (2001).The Sociological Foundations of Organizational Learning. In Dierkes, Handbook of Organizational Learning and Knowledge. Oxford: Oxford University Press.

Mcdermott (2004). How to Avoid a Mid-Life Crisis in Your CoPs: Uncovering Six Keys to Sustaining Communities, KM Review 7,(2),10.

Murphy (2008). Developmental Relationships in the dynamic library environment: Re-conceptualizing mentoring for the future, The Journal of knowledge organisational learning Management 14 (1), 62-73

Pemberton, Mavin \& Stalker (2007). Scratching beneath the Surface of Communities of (Mal) practice in the learning organization. The International Journal of Knowledge and Organizational Learning Management 14, no. 1 (2007), pp.62-73

Smith \& Mckeen (2003). Creating and facilitating communities of practice. In C. W. Holsapple, (Eds.) Handbook on Knowledge Management 1: Knowledge Matters, NY: Springer, pp.393-408

Stacey (2001). Complex Response Processes in Organizations: learning and knowledge creation. London: Routledge.

Stuckey \& Smith (2004). Building Sustainable Communities of Practice In P. M. Hildreth \& C.K. Hershey (Eds). Knowledge networks: Innovation Through communities of practice. PA: Idea Group Publishing, 150-164

University Of Ibadan, College Of Medicine Library (2014). Available from: http://www.odeku.library.ui.edu.ng. [accessed on 11/01/2014].

Wenger (1998). Communities of Practice: learning, meaning and identity. Cambridge: Cambridge University Press.

Wenger (2001). Supporting Communities of Practice: A survey of Community oriented technologies. Available: http://www.ewenger.com/tech/index.html (accessed 10 Jan.2014)

Wenger, Mcdermott \& Synder (2002).Cultivating Communities of Practice: A Guide to Managing Knowledge. Boston, MA: Harvard Business School Press.

Zappavigna (2006). Tacit knowledge in communities of practice. In Coakes,E., Clarke,S.(Eds.), Encyclopedia of communities of practice in 
information and Knowledge Management, idea Group, Hershey, pp.508-13. Coakes and Clark, "The Concept of Communities of Practice,” pp.93. 